\title{
Electronic Learning Industrial Environment System (eLINS) for Academia-Industry Collaboration
}

\author{
Nor Azliana Akmal Jamaludin and Shamsul Sahibuddin, Member, IACSIT
}

\begin{abstract}
The gaps identified were partly transformed into prototyping which provided prove of the concept. The proven concept used the requirements gathered to create the functionality for the electronic Learning Industrial eNvironment System (eLINS). The purpose of eLINS is to be the tool that accommodates the Requirements Engineering Project-Based Learning (RE PjBL). This paper will begin with the discussion of functionality which emerged as use cases. The class diagram will have all of the requirements/stories that accumulated from the Literature Review and the interpretation from those requirements that had an input on use case identification. All the inputs had an overview on the eLIN system that acted as a medium that allowed Industry practitioners to share their experiences in doing their projects (case studies), students to upload the deliverables (SRS), and lecturers to be able to monitor student tasks. Future work will be focusing on the result and analysis of eLINS usability.
\end{abstract}

Index Terms - Tools, requirement engineering, project-based Learning, eLearning, academia-industry collaboration, functionality, interface.

\section{INTRODUCTION}

The requirements for the eLIN system were derived from the analysis. Due to some concerns from the analysis, some Requirements management that refers to the three main concerns suggested by [1] will be followed in order to help students deliver a quality Software Requirements Specification (SRS). Then, the electronic Learning Indsutrial eNvironment System framework is established.

The purpose in including a working prototype into this research was to facilitate the Requirements Engineering Project-Based Learning (RE PjBL) [2]-[6]. Specifically, the eLINS was used to accommodate students in delivering the quality SRS and managing the teamwork and time needed to complete the project assigned by the lecturer. The eLINS also accommodated the students to clearly understand what they needed to do to successfully complete their projects. At the same time, the lecturer provided the exact guidelines and directions to the student on how to start and finish their projects recurrently three times before the students were allowed to choose their own project title. The three projects, known as case studies, were gathered from various software

Manuscript received June 18, 2013; revised September 12, 2013.

Nor Azliana Akmal Jamaludin is with Faculty of Computer Science \& Information Technology, Universiti Selangor, Malaysia, Advanced of Informatic System. (e-mail: norazliana@unisel.edu.my).

Shamsul Sahibuddin was with Universiti Teknologi Malaysia Kuala Lumpur, Malaysia (e-mail: shamsul@utm.my). industries which provided the materials that would be included in the SRS.

\section{THE ELINS REQUIREMENT IDENTIFICATION}

Table I shows the requirements identification derived from the results and analysis in the [7]. Then, the use case was identified for each requirement. The use case could belong to one or more requirement that has the same meaning like UC007_Upload SRS by version to ensure that the students would learn the knowledge and skills.

TABLE I: REQUIREMENTS IDENTIFICATION

\begin{tabular}{|l|l|}
\hline Requirements Identification & \multicolumn{1}{|c|}{ Use Case Identification } \\
\hline Q1e_Project & UC001_Upload Case study \\
Q1c_Case study & UC002_View Project \\
& UC008_Create Industry Link \\
& UC006_Create Student Group Project \\
Q2f_Clear do something & UC003_Create Discussion \\
Q2e_Discussed lesson learned & UC004_View Past Solution \\
& UC005_Calculate Mark \\
Q3f_Group project & UC006_Create a Student Group Project \\
Q3c_Identify final solution & UC007_Upload SRS by version \\
Q3h_Establish goal & UC001_Upload Case study \\
Q3d_Collaborative writing & UC008_Create Industry Link \\
Q31_Industry collaboration & UC009_Create Lecturer Monitoring \\
Q3n_Working prototype & Channel \\
Q3n_Leadership & \\
Management & UC003_Create Discussion \\
Q4d_Face-to-face & \\
Q4b_Brainstorming & UC007_Upload SRS by version \\
Q4e_Workshop & \\
Q5c_Organization Doc & \\
Additional Requirement Identification for eLIN system \\
\hline UC010_RegisterNewUser UC019_UploadedFile \\
UC011_Login \\
UC012_Logout \\
UC013_Home \\
UC014_Forum \\
UC015_PastSolution \\
UC016_FAQ \\
UC017_AddNewProject \\
UC018_AssignProject \\
UC018_DisbandGroup
\end{tabular}

In the meantime, it indirectly showed their attitude based on the activities of Q3f_Group project, Q3c_Identify final solution, Q3h_Establish goal, Q3d_Collaborative writing, Q31_Industry collaboration, Q3n_Working prototype, and Q3n_Leadership Management. The use case had to cater to the related requirements based on the interpretation of each requirement.

\section{THE ARCHITECTURE FOR ELINS DEVELOPMENT}

The researcher suggests that students use and experience the industry tools (e.g. IBM RequisitePro) to assist them in capturing and designing the user requirements and specifications. This will convert the students to graduates equipped with the knowledge and skills that will help them 
make a smooth and competent transition from student to employee [8]. Universities, being aware of employer needs,

are using these resources to provide students with experience in real world practices.

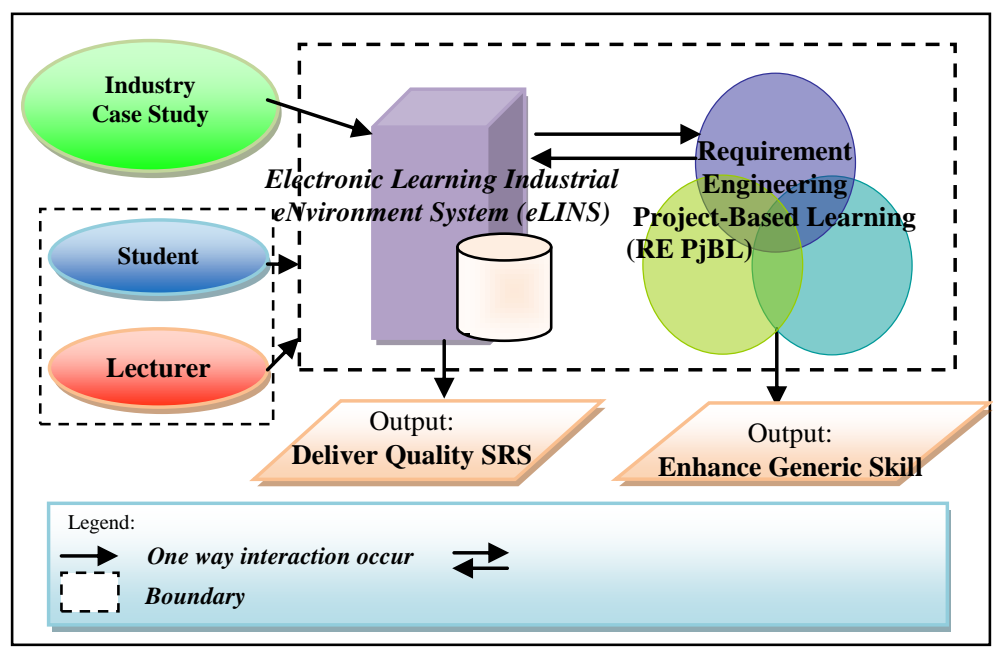

Fig. 1. Electronic learning industrial eNvironment system (eLINS) framework.

\section{eLIN System Interface}

\begin{tabular}{|c|c|c|c|c|}
\hline $\begin{array}{c}\text { Public } \\
\text { Users } \\
\text { Login }\end{array}$ & $\begin{array}{c}\text { Forms } \\
\text { Manag } \\
\text { er }\end{array}$ & $\begin{array}{c}\text { Solutions Upload } \\
\text { \& Retrieval } \\
\text { Manager }\end{array}$ & $\begin{array}{c}\text { Discussio } \\
\text { n Manager }\end{array}$ & $\begin{array}{c}\text { View } \\
\text { Manager }\end{array}$ \\
\hline
\end{tabular}

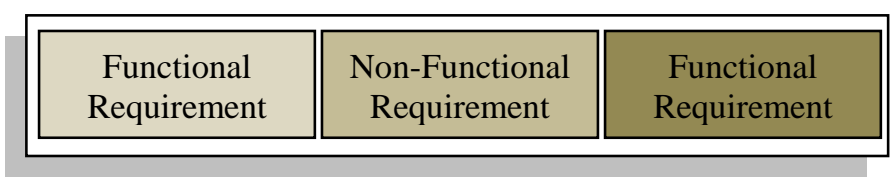

\section{eLINS Database}

Fig. 2. The architecture of the eLIN system.

This method of education through experience is the most effective as students are able to use tools similar or the same as those used in the industry [9].

The architecture (refer Fig. 2) of the eLIN system will use the web application as host. In the beginning, the system will authenticate the public user using the login page as long as they are registered as one of public users that is accommodated by the forms manager.

Software Architecture will lead the entire system infrastructure for the electronic Learning Industrial eNvironment system. The interaction begins with industry practitioners, students, and lecturers who will be referred to as public users. The forms manager provides registration forms, add new project forms, create a group forms, and comment forms.

Solution uploads and the retrieval manager will be used for the students in uploading their solutions to the case study assigned by the lecturers and for the lecturers in downloading the solution to give a particular mark for each solution and by each group of students. The discussions manager will be used to create a forum which allows registered public users to discuss their opinions, problems, and solutions on the page.

The view manager is to accommodate industry personnel to review the case studies that have been uploaded. In addition, this manager focuses more on generating reports for the uploaded solutions and marks given by the lecturers.
In order to facilitate communication among the public users [2], the repository database uses MySQL which has the strength to store more than 1,999 data from public users. The database will be able to connect directly to the code that is using $\mathrm{PhP}$. PhP [9] was considered to be used in this development because it is an open source and the availability of this programming language can be used without the need for a license. Therefore, it is suitable for a university which is much more likely to start a development in software requirements without any cost [2]. All of the application servers and repository databases will be connected to the public user through the Internet (Wide Area Network) connection. The physical architecture requirements for the eLIN system are shown in Table II. Each item column has a description and specification of the software and hardware that will be used in the eLIN system development.

TABLE II: SOFTWARE AND HARDWARE SPECIFICATIONS FOR THE ELIN SYSTEM

\begin{tabular}{|l|l|}
\hline Item & Description \\
\hline Public users & $\begin{array}{l}\text { - Industry (Practitioners), lecturers, students, } \\
- \text { Access the portal by one or more public users } \\
\text { using the Internet }\end{array}$ \\
\hline Internet & Wide Area Network (WAN) \\
\hline $\begin{array}{l}\text { Web } \\
\text { Spplication }\end{array}$ & Hosting the eLIN System \\
\hline eLIN system & $\begin{array}{l}\text { Holds the key to authenticate requirement tools; } \\
\text { store student's deliverables }\end{array}$ \\
\hline Database & $\begin{array}{l}\text { The database will store all the deliverables from the } \\
\text { student project, marks, student information, } \\
\text { practitioners detail, case study details and lecturers. }\end{array}$ \\
\hline
\end{tabular}

\section{GRAPHICAL USER INTERFACE (GUI)}

\section{A. Main Interface}

For simplicity, the prototype of the electronic Learning Industrial eNvironment system allots its capabilities to threepublic users, who are Industry Personnel, Student, and Lecturer. The main purpose of this prototype is to be a medium for these public users to interact using the discussion features. All the questions from these public users can be 
discussed and answered through the discussion features that are available on the page.

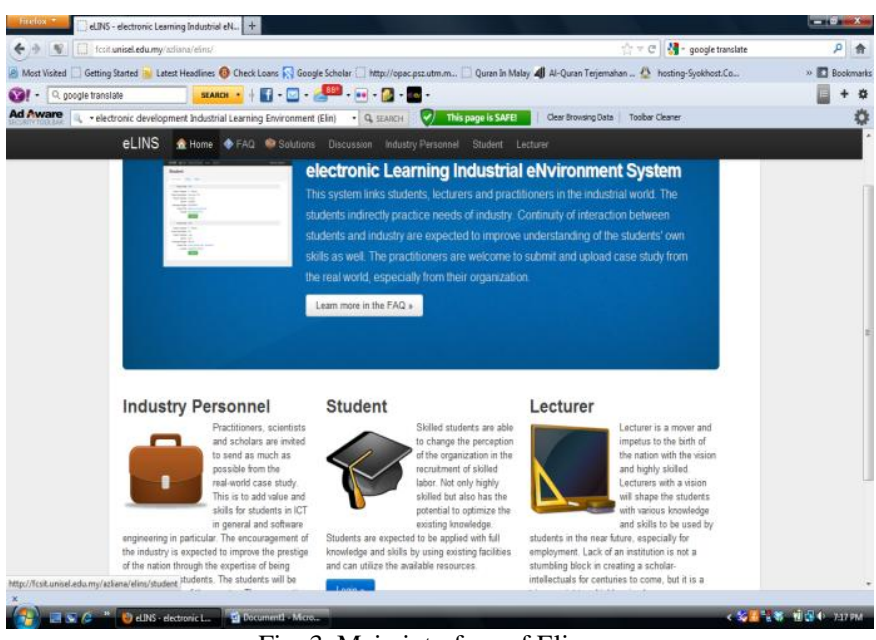

Fig. 3. Main interface of Elins.

Each public user who is able to access the eLIN system must first become a registered user by filling out the registration form. Then, the public users can start using the eLIN system by logging in to the specific user (e.g. if a user works in the industry, they can only log in to use industry personnel features only). Other public user must follow a similar process (refer Fig. 3 and Table III).

TABLE III: PUBLIC USER DESCRIPTION IN ELINS

\begin{tabular}{|l|l|}
\hline Public User & Description \\
\hline Lecturer & $\begin{array}{l}\text { The main purpose of this public user is to monitor all of } \\
\text { the processes in the eLIN system. This user should assign } \\
\text { the available projects (case study from industry) to the } \\
\text { students and mark the solutions that can be uploaded by } \\
\text { the student as a reward. }\end{array}$ \\
\hline Industry & $\begin{array}{l}\text { This public user is expected to provide previous project } \\
\text { explanations which contributes to the weaknesses and } \\
\text { success of the ICT software development as a case study. } \\
\text { In addition, this public user can briefly describe the } \\
\text { project's purpose, timeline, budget and upload the file in } \\
\text { pdf format. The uploaded file is a case study which is } \\
\text { expected to have the functionality, non-functionality, } \\
\text { and the process of the overall ICT software development } \\
\text { project which have been completed or are still in } \\
\text { progress. }\end{array}$ \\
\hline Student & $\begin{array}{l}\text { This public user needs to form and create his/her own } \\
\text { group members in the eLIN system. They should submit } \\
\text { the requirements specification (Software Requirements } \\
\text { Specification (SRS)) to practice in the understanding of } \\
\text { requirements engineering process. This public user is } \\
\text { able to upload the SRS as many times as needed if they } \\
\text { need to make any changes before the deadline. }\end{array}$ \\
\hline
\end{tabular}

At the top of the main page, guests and public users can also look at the previous solutions which are in the form of uploaded files made by the students that have been locked by the lecturer after the final solutions were marked. Industry personnel can use the previous solutions as a benchmark and to get some ideas on how to do in-house projects. A Frequent Asked Questions (FAQ) feature will help facilitate public users in the use of the eLIN system.

\section{B. Lecturer Functionality}

The operation of lecturer functionality can be successful if the students form their groups and the industry personnel uploaded their case studies (project experience). Then by selecting the project category, the lecturer can look directly at the summary of each case study uploaded by the industry personnel. The summary will consist of attributes like Project Title, Project Category, Project Description, Project Timeline, Ref. No. (Reference Number), Estimated Budget, Project File, and Created (Date). The lecturer can also create a session, check the list of students for the current semester, and check the groups that have been formed by students so that they can be assigned a case study.

Once the lecturer is satisfied and wants to proceed in assigning the tasks to the students, the lecturer needs to click the Group tab at the top of the page. For each group, the lecturer can see the students' Matriculation numbers (student Matric Number), Name (student name) and the group name. Then, the lecture can choose which group to assign the new project to by clicking the "Assign Project" button. That group will then get the "Assigned" project. But, if the group is no longer available, or if the student has requested to change their group, then the current group of students needs to be removed from the list by clicking "Disband Group". In addition, the lecturer can also award marks for students' work and discuss the evaluation results with the students on Student discussion page. This discussion page is important and convenient as it provides space for lecturers to not only discuss results but also to put in encouraging words to motivate students to take up the task as well as to help students understand the task properly.

\section{Student Functionality}

The first step that the student has to do is to register in the system and create a group by drafting new members. Next, the student will be assigned a case by the lecturer. The student can only view the case studies that have been assigned by the lecturer (refer Fig. 4). If the case study was not assigned, the student will not be able to view it. If the student can view the case study assigned to them, then the student can start reading to help them get a better understanding of the details in the case study. The student is expected to be innovative and think creatively, learn how to work together as a team, develop their technological knowledge and skills, and have a sense of public-spiritedness.

The students can start doing the requirements specification by reviewing the details of the case study. They need to first understand the SRS template if they are to produce the correct, feasible, necessary, prioritized, verifiable, unambiguous, and traceable deliverables (SRS). The student is allowed to upload more than one solution to the case study (refer Fig. 5). This is important as it makes them realize that the requirements can change and the deliverables can be modified by applying the versioning concept.

The date of the uploaded solution will be captured in order to prevent students from failing to submit their design within the deadline. If students submit after deadline, points will be deducted from their final mark. The mark will be given as a reward for the students in order to motivate them to do the task. If the students have a problem and want to discuss it among themselves, then the students can start a private online conversation or interaction to demonstrate that they can collaborate and work together to produce the SRS. The students will be able to submit a right SRS before the deadline if they have good leadership management skills. 


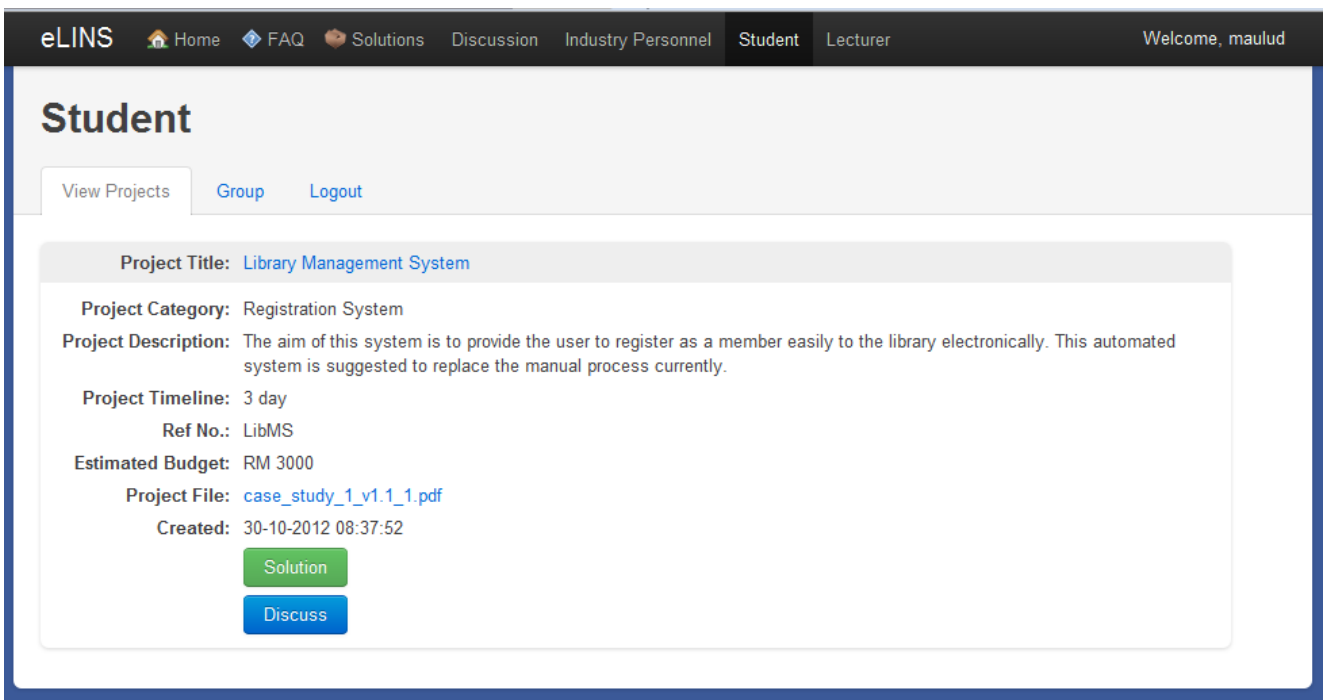

Fig. 4. Student view.

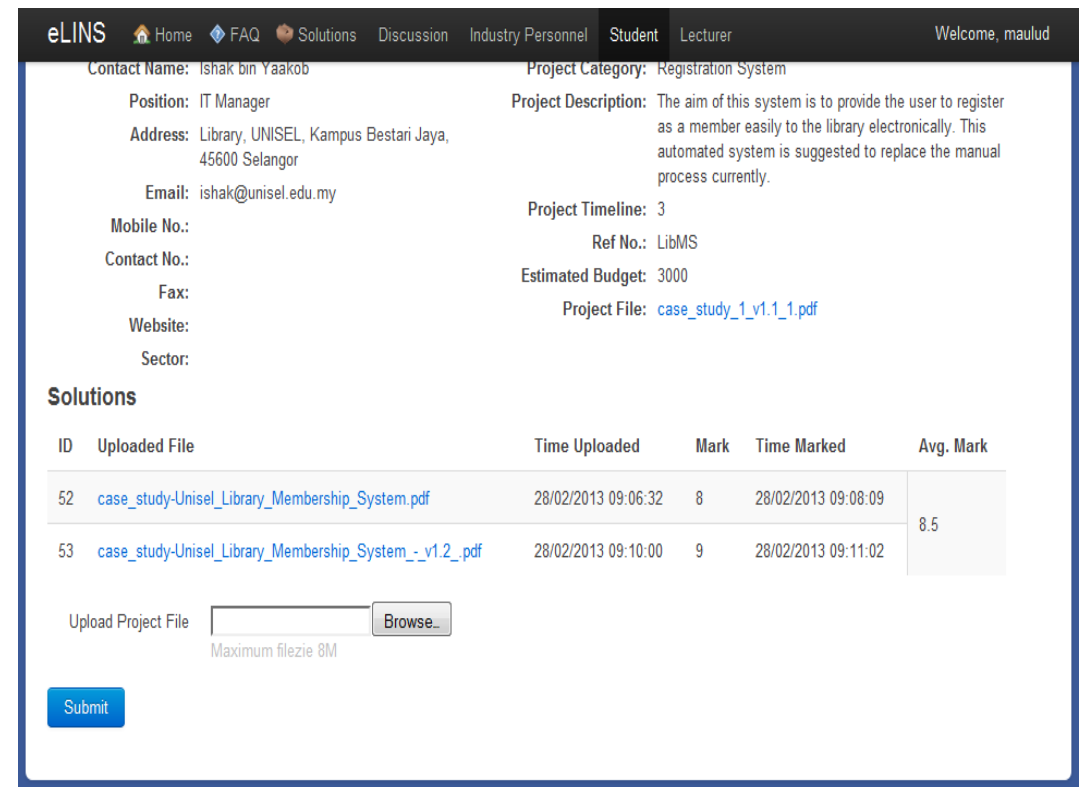

Fig. 5. Track changes of the solution.

\section{DISCUSSION}

The connection of learning and student development was instigated due to the interaction among team members and between the students and lecturer, doing collaborative work, and communicating effectively through websites. The students were able to develop their own leadership/management skills in managing their time to meet the deadline of the given case study.

\section{A. Understand}

The understanding of the requirements elements depends on student interest. If the student is interested in the subject, they will easily understand the concept (knowledge) and skill.

\section{B. Internet Connection and Communication}

The student can stay up-to-date with the latest information given by the lecturer if they are connected to the Internet. The student can also have more interaction with the team member and between other students and lecturers.

\section{The File System/Redundancy}

The students need to save and modify their computer's hard drive before they can upload the SRS softcopy into the system.

\section{Reward}

Students do not seem to realize the importance of requirements unless they are prompted by a reward or extra marks.

\section{E. Plagiarism}

The eLIN system cannot detect plagiarism. As an example, group A submits their solution early. Then, group B asks group A to help them. But group B will not be doing the task on their own if they simply copy the solution with little or no modification, because the basic idea is still the same as that of group A.

\section{F. Repeatable}

The enhancement of skill is positively increase after a few assessments did by the students. The students become more responsible in their task in submitting the task according to the dateline. 


\section{Conclusion}

The development process can only be accomplished after the completion of the analysis using the Rasch model. Both of the analyses include the requirements to obtain the prototype that is to be developed. In short, this prototype is a tool to facilitate RE PjBL. The prototype has been consolidated so that it can store in detail, all of the students' engineering requirements project work. The prototype is capable of connecting students with industry personnel and lecturers for closer monitoring. Students can communicate through the medium provided in the system such as the forums. This system has security features for each user through the use of login passwords.

Students who have registered with the system will receive a project case study from the lecturer. However, it is compulsory for the students to form a group in order to receive a project from the lecturers. After the students receive the project, they must complete the project in accordance with a predetermined period. During the given period, students who have concerns may ask other team members, lecturers, and/or industry personnel through discussion spaces. Students can also upload completed projects instantaneously. However, if any corrections need to be made, students can still edit and upload the project again before the time expires.

Projects that have been successfully completed can be seen by the lecturers directly. Lecturers can give points to projects that have been uploaded. An average overall score will be given to each of the projects of the students. Through this system, the lecturers are able to establish the extent of understanding of the students about the project given to them. Marks will be awarded to students according to the accuracy of their work within the stipulated time period.

Each project assigned in the form of a case study is received from industry personnel. Industry personnel who wish to contribute a case study for the education needs of students can upload their case study after signing in to the system. The system allows industry personnel to upload and view student projects that have been uploaded into the system personnel. Industry personnel can also be constructive members by offering comments and suggestions through the discussion space.

In addition, the basic requirements of the eLIN system, indirectly, are well accomplished as they complement the main part of Requirements Engineering Project-Based Learning (RE PjBL) attributes. However, there are still many weaknesses. Therefore, continuous improvement of the prototype is recommended for future use. As it is now, there are no editing functions which public users can use to edit their personal information if necessary once they were registered as Public Users. Nevertheless, the Industry Personnel can edit their case study information if needed.

The uploading solutions should be added during the discussion to show their progress in between students' uploading of updated solution on solutions page. The deliverables or the Software Requirements Specification (SRS) should appear on the page to make it easier for each team member to update and revise them. Furthermore, the lecturer should be allowed to customize the functions so that it can be used for the requirements specification. Other than that, there are no reasons to say that this nfrastructure cannot be setup for each university because it is the cheapest way as it uses open source. This can be very helpful to universities with financial constraints.

\section{REFERENCES}

[1] A. Amsler and N. Ron, "Blazing a web CMS trail at the University of Delaware," in Proc. the 36th annual ACM SIGUCCS fall conference: moving mountains, blazing trails, ACM, 2008, pp. 137-140.

[2] N. A. A. Jamaludin, S. Sahibuddin, M. N. H. Hashim, and S. A. Shaharuddin, "Development of electronic Learning Industrial eNvironment (eLIN) System for Requirement Engineering Education,' Chengdu, IACSIT, 2011.

[3] N. A. A. Jamaludin and S. Sahibuddin, "Development Strategy using Cognitive Domain in e-Requirement Engineering Learning System," International Journal of Computer Science Issues, vol. 8, issue 5, September 2011, pp. 1694-0814.

[4] N. A. A. Jamaludin and S. Sahibuddin, "Readiness of Requirement Engineering towards Global Collaboration and Communication," International Journal of Computer Trends and Technology, July-Aug. issue 2011.

[5] N. A. A. Jamaludin and S. Sahibuddin, K. Jusoff, and N. H. Hidayat, "Development of a Project-Based Learning Approach in Requirement Engineering," International Journal of Computer Science and Information Security (IJCSIS), USA, 2010.

[6] N. A. A. Jamaludin and S. Sahibuddin, "Challenges of a Project-Based Learning Approach towards Requirement Engineering," 10th WSEAS International Conference on Software Engineering, Parallel and Distributed Systems (SEPADS '11). ISI. Proceeding, Cambridge, United Kingdom, 2011.

[7] N. A. A. Jamaludin and S. Sahibuddin, "Measurement of Rasch Analysis towards Requirement Engineering Education: Industry Perspective," in Proc. Applied Mathematics in Electrical and Computer Engineering, Harvard University, United States, ISI, 2012.

[8] D. J. Bagert, N. P. Daniel, and S. Hossein, "Software Engineering Education, Training, and Research: The Legacy of Nancy Mead," IEEE 21st Conference on Software Engineering Education and Training, 2008.

[9] B.-Y. Muli and E. V. Hensbergen, "Open source as a foundation for systems research,” ACM SIGOPS Operating Systems Review, vol. 42, no. 1, 2008, pp. 2-4.

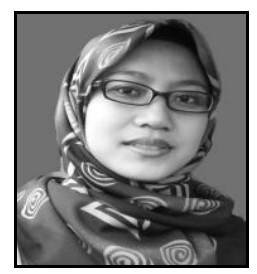

Nor Azliana Akmal Jamaludin is a lecturer for bachelor of science software engineering and head of Developer for master degree software engineering program at Universiti Industri Selangor. She received the Master Degree in Computer Science (Real-Time Software Engineering) from Advanced Informatics School (formerly known as Centre for Advanced Software Engineering (CASE), Universiti Teknologi Malaysia, in 2004. Currently, she is doing her Doctorate in Computer Science, specialize in Software Engineering at UTM and supervise by Prof. Dr. Shamsul Sahibuddin. She is a member of Malaysian Software Engineering Interest Group, Malaysia. Her field of expertise is in software requirement, analysis, system integration, and e-learning. Her current research interest is on techniques that can enhance skill among Software Engineering undergraduate of higher institutions in Malaysia using machine learning system.

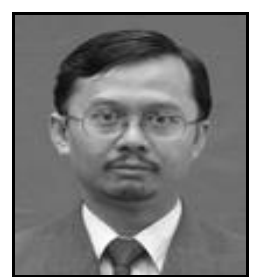

Shamsul Sahibuddin received the $\mathrm{PhD}$ in computer science at Aston University, Birmingham, United Kingdom in 1998 and master science (computer science) at Central Michigan University, Mt. Pleasant, Michigan in 1988. He is currently a Dean / Professor at Advanced Informatics School, Universiti Teknologi Malaysia (UTM) and has been a Member of the Program Committee for Asia-Pacific Conference on Software Engineering. His field of expertise is in software requirement, software modelling technique, software development and software process improvement. He has been very active in scholarly journals-book writing and publishing. 